\title{
Problems and Challenges Faced by the Rural Women: A Case Study of Balochistan
}

\author{
Dr. Immamuddin Khoso \\ IBA-University of Sindh-Jamshoro, Pakistan \\ Kamran Shafiq \\ COMSATS-Abbott bad, Pakistan \\ E-mail: kamranhashmi@ciit.net.pk \\ Asad Raza Abdi \\ Assistant Professor \\ Department of Economic, Shah Abdul Latif University, Khairpur, Pakistan \\ Faiz. M. Shaikih \\ Assistat Professor \\ SZABAC-Dokri-Jacobabad, Sindh, Pakistan \\ E-mail: faizmuhammed_2000@yahoo.com
}

\begin{abstract}
The current research addressed the issue of challenges faced by the rural women in Balochistan. A qualitative research were conducted on various parts of the Balochistan, Data were collected from 300 respondents five districts of Balochistan i.e. Turbat, Gawader, Sibbi, Pashen and Khuzdar Districts by using simple random technique. It was revealed that women in Balochistan are facing lot $\mathrm{f}$ problems like karo Kari, sexual harassments by their Tribal Waderas and feeling unsecure. Women are totally deprived from the basic rights. According to our research about $80 \%$ of the Karo Kari cases are based on Bias basis there was no reality. It was further revealed that women are facing difficulties and after Watta satta marriages they feel unsecure. Government and NGOs can play role to educate those women about their basic rights. Women are deprived from their basic rights in Balochistan. In most of the cases they are illegally raped with their feudal and in many cases they were married with 60 years old man without their wishes.
\end{abstract}

Keywords: Problems, Challenges, Rural women, Balochistan

\section{INTRODUCTION}

The current research addressed crucial issues which are faced by the Rural Women in Balochistan. In Balochistan women is deprived from the basic rights. Several complex yet inter-connected institutionalized social and cultural factors have kept women particularly vulnerable to the violence directed at them. Domestic violence is a structural rather than causal problem. It is the family's structure which leads to or legitimizes the acts, emotions or phenomena that are identified as the causes of domestic violence. The supremacy of the male and subordination of the female assumed to be the part of the culture and even to have sanction of the religion is responsible for the acceptability of the pervasive features of domestic violence. In Balochistan a patriarchal society in which women are treated as chattel given or acquired through arranged marriages to spend their lives in the service of male dominated social system. Strict family, tribal and traditional Islamic values permeate the society which views the women as personal property of male family members, owned by father or brothers before marriage and husband after marriage. This commoditization of women is one of the main factors contributing to violence against women on a daily basis where approximately seventy percent to ninety percent women are subjected to domestic violence (Note 1). A rape occurs in Pakistan every two hours with one in every 12,500 women being victims of rape. Five women per day are killed and two women per day in the region of Punjab alone are kidnapped (Note 2). The dehumanization that results from status of women as property takes atrocious forms, making various degrees of violence possible. The misinterpretation of Islamic view regarding 
protection results in their suppression physically, mentally and emotionally. In addition the dual constructs of women as property (that dehumanizes women) and women as honor (that sexualizes women) sets the stage for violence against women. "The interplay of tribal codes, Islamic Laws, Indo British judicial traditions and constancy traditions has created an atmosphere of oppression around woman (Note 3)." Keeping in view the areas identified by the secondary researches in Pakistan, the objectives identified by this primary research are to:

i) Identify the root causes of domestic violence against women

ii) Determine its state of existence and key areas of domestic violence

iii) Judge the level of awareness about the issues of domestic violence

iv Suggest remedies to reduce the prevalence of domestic violence in women

The report begins by providing a brief background of the research and states the significance of this study. It then explains the conceptual framework which has guided the study, representing the underlying causes of domestic violence symbolically with a tree. This section is followed by the research design, which explains the methodology, and the specific methods used in conducting this research and also delineate the process of data collection. The report then presents the findings of the study that were obtained through the qualitative and quantitative methods and then uses the conceptual framework to analyze these results. The macro level issue that further perpetuates the domestic violence, which is part of the conceptual framework, is also analyzed in detail in the following chapter. Finally, the paper concludes with a note on the limitations and a list of policy recommendations.

\section{Stove Burning}

Over the past decades murderers attempted murder by stove burning has become more common indication of increased marital violence. Deaths by stove burning are generally attributed to be accidental bursting of stoves with onus on manufacturer or the carelessness and ignorance of women using the stove. These incidents have witnessed a phenomenal increase. An informal survey estimated that the number of deaths as a consequence of stove blast was 800 in 1989, 1100 in 1989 and 1800 in 1991 (Note 4). The number of women who died of stove burns in the first six months of 1992 was 500 compared to 370 murders that took place at the same time. The study of women division in 1989 revealed that at least $50 \%$ of these deaths were murders linked to domestic disputes.

\section{Karo-kari in Balouchistan (Honour Killings)}

Over the past few years, an increased incidence of karo-kari 'blackened man, blackened woman' in Balochistan has further blotted Pakistan's already negative women's right's record. Rooted in patriarchal and cultural perceptions of women as male property, karo-kari ostensibly takes place to avenge family 'honour' when a woman violates tribal or cultural norms. Karo-kari is carried out when a woman and man have an illicit relationship, or are even suspected of having one, since public perception of the woman's guilt is considered sufficient to taint family 'honour'. Reports indicate that inevitably, the practice targets women, who are never given an opportunity to defend themselves against the allegations. Perceived as the embodiment of honour of their family by entering an adulterous relationship. Thus, both real and perceived the women indirectly challenge the social order as a whole. She becomes kari (Sindhi) Siah Kari (Baluch). A large proportion of murder in the name of honour - are carried out because a couple has married or wishes to marry against the family will. Karo-kari has also taken place in situations when women seek divorce, and sometime for defiling the family or tribal 'honour' by being raped. Karis remain dishonoured even after death. Their dead bodies are thrown in rivers or buried in special hidden kari graveyards. Nobody mourns for them or honours their memory by performing the relevant rites. Karos by contrast are reportedly buried in the communal graveyard (Note 5). The distinction between a woman being guilty and a woman being alleged to be guilty of illicit sex is irrelevant. What impacts on the man's honour is the public perception, the belief of her infidelity. Rumour, belief, insinuation are enough to defile honour and demand remedial action: the killing of women. Two main factors contribute to violence against women in the name of honour: women's commoditisation and conceptions of honour. The end result is that the right to life of women in Pakistan is conditional on their obeying social norms and traditions. The concept of women as an object or commodity, not a human being endowed with dignity and rights equal to those of men, is deeply rooted in the tribal culture. Dr Tahira Shahid Khan of Shirkatgah, a woman's resource centre, points out: "Women are considered the property of the males in their family irrespective of their class, ethnic or religious groups. The owner of the property has the right to decide its fate

\section{Killings under the pretext of honour}

"Honour killing was punishment for violating the honour codes but the tribes have subverted the custom of killing not for honour but to obtain the compensation that the tribal settlement awards to the aggrieved person", Nafisa Shah summarizes.38 In honour killings if both the kari and karo are killed, the matter ends; if only the 
kari is killed and the karo escapes -- as is often the case - he has to compensate the affected man, for the damage to honour he inflicted, for the woman's worth who was killed and to have his own life spared (Note 7). This provides easy opportunities for the unscrupulous to make money, obtain a woman in supposed compensation or to conceal other crimes. As Nafisa Shah puts it, a whole 'honour killing industry' has sprung up with a range of stakeholders including tribe's people, police administration and tribal mediators. "Vested interests ... use the excuse of honour as a blanket cover for a multitude of sins." (Note 8) The desire to obtain land may also lie behind some fake honour killings. Unable to repay loans, some men are known to have killed a woman of their own family to implicate someone in the debtor's family to ensure the loan would be extinguished in compensation.

\section{Watta Satta Marriages}

The Practice of Watta Satta in which a brother and sister are married to another pair of siblings continues unabated. In these barter trade marriages, if there is no exchange match available at the time, a pregnant woman in the family pledges to give her child when it is born. This custom prevails not only amongst the lower classes, in order to cut down demand of dowry but also amongst middle and upper classes. Those marriages involve abuse of two women whose marital happiness depends on actors outside their marriage. The marital or other trouble in are household would effect the relations between husband wife in the other household. S., a woman serving a life sentence for the murder of her husband in Multan jail related a story of Watta Satta marriage gone out of control. Apparently, she was given to her husband in marriage of the understanding that her husband's sister would be given to her brother as soon as she was seven year old.

\section{Rape and Sexual Assault}

Rape or forcible sexual intercourse is one of the ugliest forms of violence against women and girls, as it does not end with the act itself. Rape victims often suffer a form of post-traumatic stress disorder, and other psychological problems especially those who have suffered extreme threats, terror and helplessness. Rape has also been described as the primary instrument of control in a patriarchal society and is often used as a mechanism of revenge or punishment. A very common perception about rape is that it is somehow the woman's fault, whether because of her provocative behavior or dress or because she ventured outside the defined permissible parameters among strangers.

\section{Conceptual Framework}

Keeping in view the different pervasive forms of domestic violence prevalent in Pakistan, a conceptual framework was developed. This conceptual framework (Figure 1), symbolizes a tree threatened from attacks of pesticides in the form of sexual, physical, psychological and economic forms of violence. The root cause of these forms of violence is the socio-cultural and religious factors and without addressing these remedial measures cannot be long-lasting. The tree gets oxygen from the environment and presently this environment further aggravates the situation due to lack oxygen supply in the form of poor judicial, medico legal and police system. This tree in totality represents the case of domestic violence.

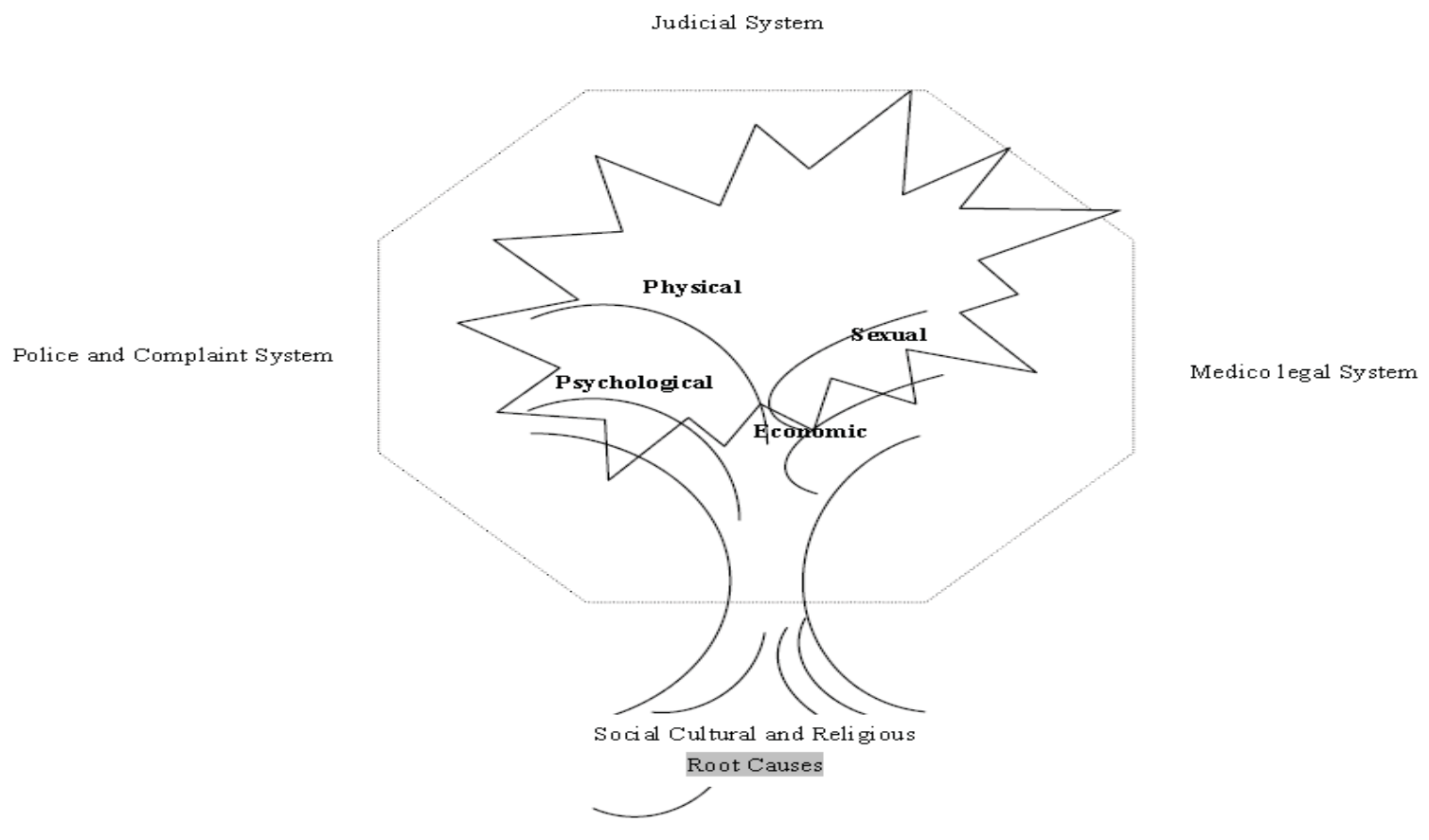


It was, therefore, these important areas that were formed part of the conceptual framework for doing the research. These areas as described earlier are explained as follows:

i) Physical Abuse

Slapping, beating, kicking, strengthening stabbing, burning including stove burning disfigurement through acid throwing, ritual honour killings, Karo Kari murder, custodial abuse, torture etc

\section{ii) Sexual Abuse}

Rape, sexual assault gang rape, coerced sex through threats, intimidation or physical force, forcing sex with others, forced marriages, child marriages, Watta satta marriages, barter marriages, (giving a women in marriage as part of the settlement of a dispute), incest.

iii) Psychological Abuse: which includes behavior that is intended to intimidate, persecute, take away custody of children, isolation, verbal aggression, constant humiliation, seclusion (confirming women to the house).

iv) Economic Abuse: includes acts as denial of funds, denial of food and basic needs and controlling access to basic health care.

\section{Data Collection Methodology}

Data were collected from 300 respondent's five districts of Balochistan i.e. Turbat, Gawader, Sibbi, Pashen and Khuzdar Districts by using simple random technique. Structural questionnaire was the basic tool for measurement.

\section{Results}

As highlighted in the conceptual framework there are basically 4 pervasive forms of violence and their prevalence in the target / study population is described as follows:

\section{i) Psychological Abuse}

As part of the psychological violence teasing is a very common phenomenon and especially happens at the time of marriage when the newly wed bride is teased for brining insufficient and inadequate dowry which is not according to the demands of the in laws. Similarly not having children even after a short period of 1 year often brings about teasing remarks. On one occasion a husband asked the health professional to check his wife even after having a number of children. Also teasing takes place when a girl is born because it is considered as a bad omen and mother is blamed for the birth of girl. Birth of a second girl child results in second marriage enforced by the husband's family. There were also instances when teasing remarks were passed by mother-in-laws to the women on the occasion of buying items from male sellers. Preceding the internal conflicts / quarrels there is a forced period of isolation, which also psychologically burdens the affectees. There were two incidents where the custody of children was retained by the husband's family. On one occasion there was a quarrel and the girl was sent to her parent's home, whereas on the other occasion the husband had died and the mother-in-law sent the women to her parent's home.

\section{ii) Physical Abuse}

There were a large number of cases of physical violence in our sample population. Beating of the wives by the husbands was considered as a right. This beating was a common practice when there were financial constraints and problems faced by the family, the dowry brought by the girls was insufficient, birth of consecutive girls, late conception, discussing violence issues with her family etc. It was found that in 7 cases girls were forced to marry against their wishes. These girls were aware because of being educated and did not want to be a life partner with uneducated and older persons. There were three cases of WATTA SATTA.

\section{iii) Sexual Abuse}

This was the most sensitive of the information regarding domestic violence and most difficult to get. Most of these cases go unreported. There were four instances when husband forced sex on their wives and in one instance certain inhumane methods of intercourse were used, which had negative reproductive health consequences. It was alarming to get information about an incest case, where a brother committed incest with her sister, who conceived and later administered abortion through dangerous and unsafe methods. There two cases where the father-in-law committed did the sexual abuse of his daughter-in-law. From among these two cases, when husband knew about this situation he 
divorced his wife and left the area, whereas in the second case father had married his teenage son with the objective of abusing his daughter-in-law. There was another instance where step son forced her step mother illicit relations.

\section{iv) Economic Abuse}

Basic rights of having access to basic necessities of life are not provided to women in this area. Even the medicines for improving the health of women are not allowed by the husbands. It came out in the focus group discussion that husbands don't allow free medicines from the Ministry of Health thinking that these are contraceptives. Using of contraceptives if considered as a sin and against the Islamic teachings and local cultural norms. Women are not allowed to work in organizations though they do work in the fields. Women are not allowed to participate in any financial decision making.

A brief summary of the results obtained during the in-depth interviews other than the instances mentioned above are presented in tabulated form on the next page.

\section{EXISTENCE OF DIFFERENT FORMS OF VIOLENCE AMONG THE SAMPLE HOUSEHOLDS}

\begin{tabular}{|c|c|c|c|c|c|c|c|c|}
\hline Type of Violence & Kinds of violence & $\begin{array}{l}\text { Parentsibro } \\
\text { thers }\end{array}$ & Husband & $\begin{array}{l}\text { Father-in- } \\
\text { law }\end{array}$ & $\begin{array}{l}\text { Mother } \\
\text {-in-law }\end{array}$ & Both & $\begin{array}{l}\text { Brothe risister } \\
\text {-in-law }\end{array}$ & Other relatives \\
\hline \multirow[t]{7}{*}{ Psychological } & Teasing & 34 & 100 & 20 & 23 & 40 & 12 & $\begin{array}{l}\text { Nephew, step son, } \\
\text { S. Father }\end{array}$ \\
\hline & $\begin{array}{l}\text { Interference in } \\
\text { privacy }\end{array}$ & 11 & 89 & 20 & 9 & 33 & 66 & S. Son \& Father \\
\hline & Unwanted to uch & 200 & 89 & 5 & 66 & 34 & 78 & S. Son \& Father \\
\hline & Teasing remarks & 100 & 212 & 34 & 39 & 50 & 60 & Nephew \\
\hline & Isolation & 123 & 213 & 40 & 66 & 44 & 40 & \\
\hline & Custody of children & & & & 20 & & & \\
\hline & $\begin{array}{ll}\text { Participation } & \text { in } \\
\text { decision making } & \end{array}$ & 10 & 11 & 23 & 37 & 78 & 55 & \\
\hline \multirow{5}{*}{$\begin{array}{l}\text { Physical } \\
\text { violence }\end{array}$} & Torture & 213 & 222 & 23 & 45 & 55 & 66 & Nephe w, Step son \\
\hline & Honour killing & 122 & 213 & 55 & 66 & 70 & 44 & \\
\hline & Buming & 80 & 78 & 70 & 23 & 89 & 77 & \\
\hline & Forced mamiage & 212 & 55 & 60 & 77 & 120 & 44 & \\
\hline & Inheritance & 5 & & & 7 & 1 & 9 & Nephe w \\
\hline \multirow[t]{6}{*}{ Sexual violence } & $\begin{array}{l}\text { By force from } \\
\text { husband }\end{array}$ & 23 & 66 & 77 & 78 & 121 & 55 & Step son \\
\hline & Threat & 56 & 67 & 73 & 43 & 123 & 88 & \\
\hline & Unwanted & 131 & 33 & 67 & & & & Step son \\
\hline & $\begin{array}{l}\text { Forced for sex with } \\
\text { others }\end{array}$ & 12 & 34 & 13 & 45 & 55 & & \\
\hline & Raped & 155 & 44 & 45 & 33 & 56 & & Step son \\
\hline & Verbal sex & 111 & 123 & 33 & 45 & 67 & 11 & Step son \\
\hline \multirow[t]{3}{*}{$\begin{array}{l}\text { Economic } \\
\text { Violence }\end{array}$} & $\begin{array}{l}\text { Non involve ment in } \\
\text { financial decisions }\end{array}$ & 23 & 33 & 25 & 44 & 38 & 22 & \\
\hline & Job permission & 34 & 24 & 66 & 66 & 45 & 65 & S.Father \\
\hline & $\begin{array}{l}\text { Provision of basic } \\
\text { necessities }\end{array}$ & 34 & 45 & 44 & 66 & 88 & 67 & \\
\hline Social Viole nce & $\begin{array}{l}\text { Restriction on social } \\
\text { interaction }\end{array}$ & 212 & 23 & 44 & 44 & 67 & 65 & S.Father \\
\hline
\end{tabular}

Sample area of population: Sample size: 300

\section{Affectees: 245}

\section{Gender Equality and Absence of an Enabling Environment - Macro Level Conditions Perpetuating Domestic Violence}

The Constitution of Pakistan in several articles guarantees gender equality. For instance, article stipulates that: "All citizens are equal before law and are entitled to equal protection of law" and article 27 states: "There shall be no discrimination on the basis of sex alone". Of the international human rights treaties relevant to the issue of honour killings, Pakistan has ratified only the UN Convention on the Elimination of All Forms of Discrimination against Women and the UN Convention on the Rights of the Child. However, both of these conventions obligate 
it to act to protect the relevant rights. The objective reality is that commitments to ensure gender equality and international legal obligations to exercise due diligence in preventing, investigating and punishing violations of rights of girls and women, have not been adhered to Pakistan has failed to ensure that legal provisions, law enforcement and judicial structures ensure the full enjoyment by women of their human rights. Many of the above mentioned manifested forms of violence are ignored, condoned, or justified by invoking religion, culture or traditional beliefs. In addition, legal and judicial institutions have failed to provide adequate safeguards against women.

\section{Strategies and Interventions}

\section{An Integrated Approach}

Domestic violence is thus a complex problem and there is no one strategy that will work in all situations. The degree to which it is sanctioned by the society and community will naturally influence the kind of strategy needed. Considering the interconnections between the factors responsible for domestic violence - gender discussed above - strategies and interventions should be designed within a comprehensive and integrated framework. A multi-layered strategy that addresses the structural causes of violence against women while providing immediate services to victim-survivors ensures sustainability and is the only strategy that has the potential to eliminate this scourge. When planning strategies and interventions, there are a variety of stakeholders that should be borne in mind. Partnerships with these stakeholders can operate on several levels at once.

- At the level of the family, the stakeholders include women, men, adolescents and children.

- Within the local community, partnerships have to be developed with traditional elders, religious leaders, community-based groups, neighborhood associations, men's groups (e.g., village farmers' associations), local councils and village level bodies. In traditional societies reliance has been on community based support mechanism to resolve issues of conflict.

- Within civil society, the range of partners includes professional groups, women's and men's groups, NGOs, the private sector, the media, academia, and trade unions.

- At the state level, strategies must be designed in partnership with the criminal justice system (the police, judiciary and lawyers); the health care system; parliament and provincial legislative bodies; and the education sector.

- Key areas for intervention include:

- advocacy and awareness raising

- education for building a culture of non-violence - curricula that teaches human rights/gender issues should be included in elementary and secondary schools.

- training

- resource development

- direct service provision to victim survivors and perpetrators

- networking and community mobilization

- direct intervention to help victim survivors rebuild their lives

- legal reform

- monitoring interventions and measures

- data collection and analysis

- early identification of 'at risk' families, communities, groups, and individuals. These areas are not mutually exclusive; interventions may touch upon several areas at once.

- Above all, five underlying principles should guide all strategies and interventions attempting to address domestic violence:

- prevention

- protection

- early intervention

- rebuilding the lives of victim-survivors 


\section{- accountability}

This section of the Digest attempts to formulate a framework for coordinated action at the policy and program level.

\section{NON-GOVERNMENTAL ORGANIZATIONS}

(NGOs), like women's organizations, have worked in partnership with government agencies and international organizations to provide a diversity of services, and education and awareness programs. Their capacity to continue to deliver a range of services should be strengthened, particularly in collaboration with state agencies. NGOs have a fundamental role to play in bringing pressure on governments to ratify, or withdraw their reservations to, the international human rights instruments such as the UDHR, CEDAW and the CRC. NGOs have played a critical role in monitoring implementation of non-treaty instruments such as the UN Declaration on the Elimination of Violence against Women, the Vienna Declaration and Program of Action, and the Beijing Declaration and Platform for Action.

THE PRIVATE SECTOR has a vested interest in addressing this problem since the costs of domestic violence to society, and industry in particular, are phenomenal in terms of low productivity, absenteeism, and staff turnover. The private sector should also be encouraged to finance preventive and support services in the local community.

THE MEDIA plays a pivotal role in both influencing and changing social norms and behavior. Repeated exposure to violence in the media has been associated with increased incidence of aggression, especially in children. In the area of domestic violence, media campaigns can help to reverse social attitudes that tolerate violence against women by questioning patterns of violent behavior accepted by families and societies.59 Collaboration with the media needs to focus on creating new messages and new responses to reduce domestic violence. Hence a conscious effort to make media professionals aware of the issues can play an important role in addressing violence against women.

RELIGIOUS LEADERS AND SCHOLARS need to re-examine interpretations of religious texts and doctrines from the perspective of promoting equality and dignity for women. Many men who abuse women justify such behavior on a religious basis, and many cultural practices that abuse and violate women are justified in the name of religion. Religious leaders at all levels have a responsibility to ensure that religious interpretations are not used to oppress women. Greater collaboration is required between research and academic institutes, women's organizations, NGOs, and service providers when conducting qualitative research to deepen understanding of the causes of domestic violence, and its physical and psychological impact on women. Such research needs to be fed back to the community so that it can lead to awareness and transformation.

\section{The criminal justice system}

LEGAL REFORM It is the responsibility of governments who have ratified international conventions and human rights instruments to harmonize their national laws in line with these instruments. One step towards upholding the right of women to equal protection under the law is to enact domestic violence legislation that specifically prohibits violence against women. Under this legislation, a woman should have protection from threats and acts of violence, safety and security for herself, her dependents and property, and assistance in continuing her life without further disruption.

THE POLICE are particularly well-positioned to provide assistance to victim-survivors, but very often their own prejudices, lack of training, and reluctance to intervene hinder them from dealing with domestic violence. Training and sensitization of police at all levels must be instituted, and guidelines must be developed to monitor police response. Police must be held accountable for their own behaviour towards victim-survivors in order to prevent secondary victimization of women at their hands.

THE JUDICIARY can strongly reinforce the message that violence is a serious criminal matter for which the abuser will be held accountable. The judge sets the tone in the courtroom and makes the most critical decisions affecting the lives of the victim, perpetrator, and children, and must therefore be sensitive to the dynamics of domestic violence in order to pass equitable verdicts. Sensitization of the judiciary to gender issues is, therefore, critical and law schools should include relevant courses in their programs.

\section{The health care system}

The health care system is well-placed to identify women who have been abused and refer them to other services, as the vast majority of women visit a health facility at some point in their lives - during pregnancy, for example, or to get treatment for themselves or their children. The reality, however, is that far from playing a proactive role, 
the health care system has usually been unresponsive to women suffering from domestic abuse. Training for health care providers is necessary to guide them on the early screening and identification of women who are suffering domestic violence. Such training, as far as possible, should be integrated into existing training: Training should be supplemented with protocols to guide health care providers to implement standards. Protocols should include procedures for documentation for legal, medical and statistical purposes; legal, ethical and privacy issues; and upto- date information on local referral services. Protocols need to be culture-specific with special attention paid to respecting the rights of women.

\section{Conclusion}

The current research explores the Domestic violence against women in Balochistan. Women are deprived from their basic rights in Balochistan. In most of the cases they are illegally raped with their feudal and in many cases they were married with 60 years old man without their wishes. Consistent support for women must be provided by all relevant sectors - the criminal justice system, health, welfare, and the private sector. Support must also be available to women via informal networks such as family, friends, neighbors, and local community groups. Men should receive one consistent message from all sectors and levels of society - that those who perpetrate violence will be held accountable. The criminal justice system must act to reinforce this message by taking action against perpetrators, as well as providing rehabilitation options for those who offend. Support services need to address associated behavior patterns such as drug and alcohol problems or the risky sexual behavior in which adolescent girls and boys may indulge as a result of being victimized themselves.

\section{References}

[Online] Available: http://www.himalmag.com/2002/july/profile_2.html

[Online] Available: http://www.pakistaneconomist

[Online] Available: www.adb.org

[Online] Available: www.imf.orgwww.Srilanka-Timeline.htm

[Online] Available: www.lanka.net/centralbank/notes.html

[Online] Available: www.priu.gov.lk/EditorialReviews.html

Aman. S. (1992). Kitchen Murders: why only women? The News $20^{\text {th }}$ June.

HAMZA ALVI. Pakistani women in a changing society Human Rights Commission of Pakistan - 1999 Report Economic Survey of Pakistan 2009-10

J.A. Rehman. (1998). The legal rights of women in Pakistan: Theory \& Practical, p. 9

Nafisa Shah. (1993). Of Female Bondage. News time, January, p.44.

Nafisa Shah. (1998). A story in black: Karo Kari Killings in upper Sindh, REUTER Foundation Paper 100 ford 1998 p.5 Newsline, April, p.18.

Simi Kamal \& Asma Khan. (1997). A study of the interplay of formal and customary laws on woman,Vol. 1, p ii.

Somnath Sen. (1992). Military Expenditure Data for Developing Countries: Methods and Measurement, in Geoffrey Lamb and Valeriana Kallab (ed.), Military Expenditure and Economic Development: A Symposium on Research Issues, Discussion Paper no.185, The World Bank, Washington, D.C.

\section{Notes}

Note 1. HAMZA ALVI: Pakistani women in a changing society.

Note 2. Human Rights Commission of Pakistan - 1999 Report.

Note 3. Simi Kamal, Asma Khan: A study of the interplay of formal and customary laws on woman,Vvol 1, 1997, p ii.

Note 4. Aman. S. Kitchen Murders: why only women? The News 20th June 1992.

Note 5. J.A. Rehman, The legal rights of women in Pakistan: Theory \& Practical, 1998, p.9.

Note 6. Nafisa Shah: "Of Female Bondage.” News time January 1993 p.44.

Note 7. Nafisa Shah: A story in black: Karo Kari Killings in upper Sindh, REUTER Foundation Paper 100 ford 1998 p.5.

Note 8. Newsline, April 1998, p.18. 